\title{
Synthesis and antimicrobial activity of the bacteriocin pediocin PA-1 and analogs thereof
}

\author{
François Bédard ${ }^{1}$, Hammami Riadh ${ }^{2}$, Séverine Zirah $^{3}$, Sylvie Rebuffat ${ }^{3}$, Ismail Fliss ${ }^{2}$, Eric Biron ${ }^{1}$ \\ ${ }^{1}$ Faculty of Pharmacy and Institute of Nutrition and Functional Foods, Université Laval, Canada \\ ${ }^{2}$ STELA Dairy Research Centre, Institute of Nutrition and Functional Foods, Université Laval, Canada \\ ${ }^{3}$ Muséum national d'Histoire Naturelle, Sorbonne Universités, France
}

https://doi.org/10.17952/35EPS.2018.235

\section{Introduction}

Bacteriocins are a family of ribosomally-synthesized antimicrobial peptides produced by a wide variety of bacteria. With their attractive antimicrobial properties and activities, these peptides are promising alternatives to conventional antibiotics in the food and animal production industry as well as veterinary and human medicine. [1-3] Among the large number of bacteriocins, we were particularly interested in pediocin PA-1, a peptide of 44 amino acids containing two disulfide bonds produced by Pedioccocus acidilactici able to inhibit the growth of several clinically relevant pathogens such as Listeria monocytogenes.[4] Despite its great potential as an antimicrobial agent, the problems associated with its production continue to limit its applicability and delay regulatory approval. To pave the way for the future use of pediocin PA-1 in different food, veterinary and medical sectors, our main objective was to develop a convenient and efficient approach to prepare bioactive pediocin PA-1.

\section{Results and Discussion}

The chemical synthesis of pediocin PA-1 has been attempted in the past but with limited success (yields below $1 \%$, use of multiple purification steps).[5] To overcome difficult couplings and prevent aggregation during peptide synthesis, PEG-based ChemMatrix resin bearing the HMPB linker was used and pseudoprolines introduced at the critical positions Val8-Thr9, Ala21-Thr22 and Ala34-Thr35 (Fig. 1). After cleavage from the resin, linear pediocin PA-1 1 was purified by HPLC and cyclized in presence of N-chlorosuccinimide to yield oxidized analogs 2a-c. After HPLC purification, the oxidized Met of $2 \mathrm{c}$ was selectively reduced to give pediocin PA-1 $3 \mathrm{c}$. Pediocin PA-1 oxidized at the Met31 position is 100X less active.6-8 This high sensitivity to aerobic oxidation strongly limits the production, storage and use of pediocin PA-1. For this reason, the Met31 was replaced by a Leu residue in analogs 4 and 5.[7,8] Finally, the Cys residues were replaced by Ala in analog 6 to determine if disulfide bonds are essential for activity. Pediocin PA-1 $3 \mathrm{c}$ thus synthesized was obtained in $11 \%$ overall yield and showed similar strong inhibition of $L$. monocytogenes $(\mathrm{MIC}=13.5 \mathrm{nM})$, similar to the bacteriocin produced naturally by $P$. acidilactici (Table 1).9 On the other hand, linear M31L analog 4 was obtained in 55\% overall yield and showed an activity comparable to that of $3 \mathrm{c}$ with a MIC of $13.5 \mathrm{nM}$ against $L$. monocytogenes (Table 1 ).

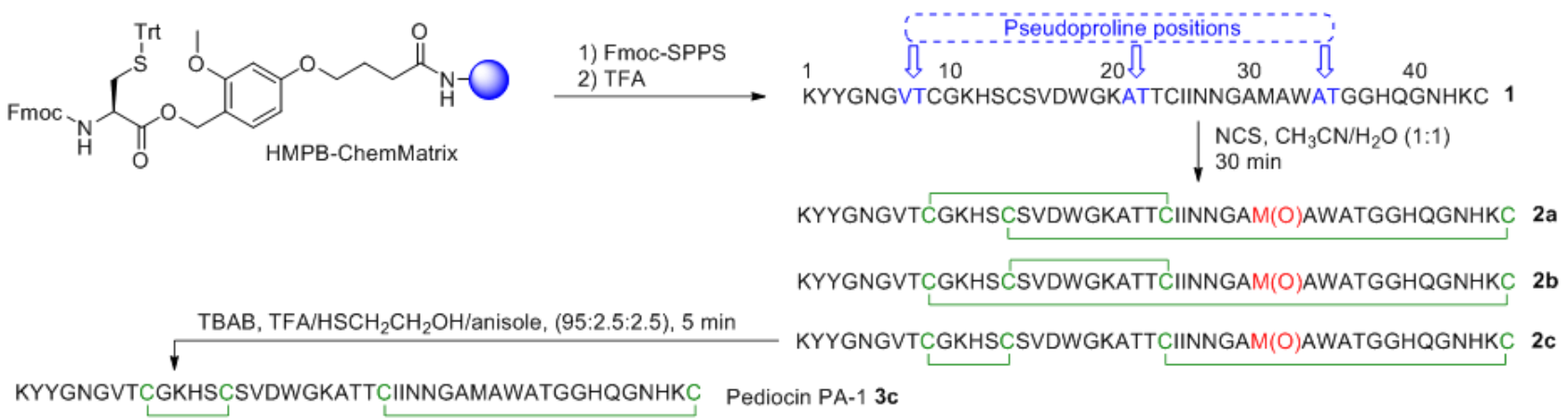

Figure 1: Synthesis of pediocin PA-1 3c and its analogs. 
Table 1: Minimal inhibitory concentrations of synthetic pediocin PA-1 3c and its analogs

\begin{tabular}{|c|c|c|}
\hline \multirow{2}{*}{ Peptide } & \multicolumn{2}{|c|}{ Minimal inhibitory concentration $^{\mathrm{a}}(\mathrm{nM})$} \\
\hline & L. ivanovii HPB28 & L. monocytogenes ATCC 19111 \\
\hline 1 KYYGNGVTCGKHSCSVDWGKATTCIINNGAMAWATGGHQGNHKC & 6.8 & 13.5 \\
\hline 2c KYYGNGVTCGKHSCSVDWGKATTCIINNGAM(O)AWATGGHQGNHKC & 1562 & 25000 \\
\hline 3a KYYGNGVTCGKHSCSVDWGKATTCIINNGAMAWATGGHQGNHKC & 27.0 & 27.0 \\
\hline 3b KYYGNGVTCGKHSCSVDWGKATTCIINNGAMAWATGGHQGNHKC & 13.5 & 13.5 \\
\hline 3c KYYGNGVTCGKHSCSVDWGKATTCIINNGAMAWATGGHQGNHKC & 6.8 & 13.5 \\
\hline 4 KYYGNGVTCGKHSCSVDWGKATTCIINNGALAWATGGHQGNHKC & 6.8 & 13.5 \\
\hline 5 KYYGNGVTCGKHSCSVDWGKATTCIINNGALAWATGGHQGNHKC & 1.7 & 13.5 \\
\hline 6 KYYGNGVTAGKHSASVDWGKATTAIINNGAMAWATGGHQGNHKA & n.a. ${ }^{b}$ & n.a. ${ }^{b}$ \\
\hline
\end{tabular}

Table 2: Spectrum of activity of linear pediocin PA-1 M31L analog 4

\begin{tabular}{lcccc}
\hline Strain & Reference & MIC $^{\mathbf{a}}(\mathbf{n M})$ & \multicolumn{2}{c}{ Diffusion assay $^{\mathrm{b}}(\mathbf{m m})$} \\
\hline Carnobacterium divergens & ATCC 35677 & 1.9 & 35 & 0 \\
Leuconostoc mesenteroides & ATCC 23386 & 1.9 & 33 & 0 \\
Listeria seeligeri & ATCC 35967 & 4.7 & 32 & 0 \\
Clostridium perfringens & AAC 1-222 & 37.8 & 25 & \\
Clostridium perfringens & AAC 1-223 & 75.7 & 22 & 9 \\
\hline
\end{tabular}

a Determined from micro-dilution assay. 'Inhibition zone diameter

As expected, the oxidized Met31 analog 2c showed an important decrease in inhibition while analog 6 was inactive, demonstrating that disulfide bonds are important for pediocin PA-1 activity. Analogs $3 \mathrm{a}$ and $3 \mathrm{~b}$ with incorrect disulfide bond pairings were 2-4 times less active (Table 1), suggesting the presence of an equilibrium in disulfide bond pairing that ultimately leads to the most stable and active conformation of pediocin PA-1 for a portion of the peptide. The equivalent antimicrobial activities observed for pediocin PA-1 $3 \mathrm{c}$ and its linear analogs 1 and 4 suggest that the disulfide bonds are formed in situ in the bioassay medium since they are essential for activity. Based on the bacterial target of pediocin PA-1, a protein Blast with the sequence of manPTS IID from L. monocytogenes (WP_003721724.1) allowed us to identify several potential sensitive strains.9 Among the tested strains with peptide 4, the strongest activity was observed against $C$. divergens, $L$. mesenteroides and $L$. seeligeri with MICs ranging from 1.9 to $4.7 \mathrm{nM}$ (Table 2). The most interesting result from this focused screening was the strong activity against Clostridium perfringens with MICs of 37.8-75.7 $\mathrm{nM}$ (Table 2).9 This important food-borne pathogen is one of the most common causes of food poisoning in North America.

In summary, a combination of solid- and solution-phase strategies was used to overcome synthetic pitfalls and produce pediocin PA-1 in good yields. Replacement of the sensitive methionine at position 31 with leucine did not affect antimicrobial activity and improved peptide stability. The linear analogs 1 and 4 were equally potent as their bicyclic counterparts3c and 5 with low nanomolar MIC against L. monocytogenes. With higher yields, increased stability and strong antimicrobial activities against major food-borne pathogens such as Listeria spp. and Clostridium perfringens, the linear M31L pediocin PA-1 analog 4 has great potential in the prevention and treatment of infections in the food and animal production industry as well as in human and veterinary medicine.

\section{Acknowledgements}

This work was supported by the Fonds de recherche du Québec-Nature et Technologie (FRQ-NT). F. Bédard thanks the FRQ-NT and Fondation de l'Université Laval for postgraduate scholarships. 


\section{References}

1. Cotter, P. D., Ross, R. P. \& Hill, C. Nat. Rev. Microbiol. 11, 95-105 (2013) DOI 10.1038/nrmicro2937

2. Mathur, H., Field, D., Rea, M.C., Cotter, P.D. Hill, C., Ross, R.P. Front. Microbiol. 8, 1205 (2017) DOI $10.3389 /$ fmicb.2017.01205

3. Ahmad, V., Khan, M.S., Jamal, Q.M.S., Alzohairy, M.A., Al Karaawi, M.A., Siddiqui, M.U. Int. J. Antimicrob. Agents 49, 1-11 (2017) DOI 10.1016/j.ijantimicag.2016.08.016

4. Henderson, J.T., Chopko, A.L., van Wassenaar, P.D. Arch. Biochem. Biophys. 295, 5-12 (1992) DOI 10.1016/0003-9861(92)90480-K

5. Bédard, F., Biron, E. Front. Microbiol. 9, 1048 (2018) DOI 10.3389/fmicb.2018.01048

6. Johnsen, L., Fimland, G., Eijsink, V. \& Nissen-Meyer, J. Appl. Environ. Microbiol. 66, 4798-4802 (2000) DOI 10.1128/aem.66.11.4798-4802.2000

7. Derksen, D. J., Boudreau, M. A. \& Vederas, J. C. ChemBioChem 9, 1898-1901 (2008) DOI 10.1002/ cbic. 200800272

8. Kaur, K., Andrew, L. C., Wishart, D. S. \& Vederas, J. C. Biochemistry 43, 9009-9020 (2004) DOI $10.1021 / \mathrm{bi036018 \textrm {e }}$

9. Bédard, F., Hammami, R., Zirah, S., Rebuffat, S., Fliss, I., Biron, E. Sci. Rep. 8, 9029 (2018) DOI $10.1038 / \mathrm{s} 41598-018-27225-3$ 